\title{
Effects of obesity on postural balance and occurrence of falls in asymptomatic adults
}

\section{Efeitos da obesidade no equilibrio postural e ocorrência de quedas em adultos assintomáticos}

\author{
Thatiane Lopes Valentim Di Paschoale Ostolin 미 , Bárbara de Barros Gonze ${ }^{\circledR[a]}$, Matheus Oliveira de \\ Jesus ${ }^{[a]}$, Rodolfo Leite Arantes ${ }^{[a, b]}$, Evandro Fornias Sperandio ${ }^{\left[{ }^{[a, b]}\right.}$, Victor Zuniga Dourado ${ }^{[a] *}$
}

[a] Universidade Federal de São Paulo (UNIFESP), Santos, SP, Brazil

[b] Instituto de Medicina Cardiovascular Angiocorpore, Santos, SP, Brazil

\section{Abstract}

Introduction: Previous studies suggested that body weight is a strong predictor for postural balance. High body mass index (BMI) presented an association with increased postural sway. However, it seems controversial since studies reported no difference between obese and control group regarding the position of the center of pressure in static postural balance (PB). Also, there is a lack of investigations about the impact of obesity on PB, free of the confound effect of cardiometabolic risk. Objective: The aim of this study was to evaluate the effects of obesity in static PB and occurrence of falls in asymptomatic adults and older adults over 40 years old. Method: The PB of 624 subjects divided into quartiles for BMI, waist-to-hip ratio, waist-to-height and fat body mass as percentage (\%FBM) was assessed with and without vision using a force platform. An MANOVA was used to determine if there were differences between quartiles and a logistic regression analysis adjusted for confounders variables were applied to determine the obesity role in the occurrence of falls. Results: We found weak to moderate bivariate correlations between obesity and static PB, which

\footnotetext{
*TLVPO: MS, e-mail: thati.ostolin@gmail.com BBG: MS, e-mail: barbara_gonze@hotmail.com MOJ: MS, e-mail: matheus.oliveira93@hotmail.com.br RLA: PhD, e-mail: arantes.r@uol.com.br EFS: PhD, e-mail: evandrosperandio@yahoo.com VZD: PhD, e-mail: vzdourado@yahoo.com.br, victor.dourado@unifesp.br
} 
became non-significant after adjustment. We found significant differences between first and fourth quartiles, especially using \%FBM. Obesity was not related to the occurrence of falls since the odds ratio values became non-significant for all the indices of obesity after adjustment. Conclusion: Obesity presents little influence on maintaining static PB and seems not to determine the occurrence of falls among subjects over 40 years old.

Keywords: Falls. Postural Balance. Obesity.

\section{Resumo}

Introdução: Estudos prévios sugerem que o peso corporal é forte preditor do equilíbrio postural. Índice de Massa Corporal (IMC) apresenta associação com oscilação corporal aumentada. Contudo, isto é controverso já que estudos reportaram que não há diferença entre obesos e grupo controle em relação ao deslocamento do centro de pressão no equilíbrio postural (EP) estático. Além disso, a literatura é escassa sobre o impacto da obesidade sem o efeito confundidor do risco cardiometabólico. Objetivo: Avaliar os efeitos da obesidade no EP estático e na ocorrência de quedas em adultos assintomáticos acima de 40 anos. Método: $O$ EP estático dos 624 indivíduos divididos segundo os quartis de IMC, relação cintura-quadril e cintura-altura e gordura corporal em porcentagem (\% GC) foi avaliado com olhos abertos e fechados usando uma plataforma de força. As diferenças entre os quartis foram determinadas por meio de uma MANOVA e o papel da obesidade na ocorrência de quedas foi analisado por meio de regressão logística ajustada pelos principais confundidores. Resultados: Obtivemos correlações bivariadas fracas a moderadas entre a obesidade e o EP estático, que, após ajuste, não foram estatisticamente significativas. Observamos diferenças significativas entre primeiro e quarto quartis, sobretudo para quartis de \%GC. A obesidade não se associou à ocorrência de quedas já que os valores de odds ratio perderam significância para todos os índices d e obesidade após o ajuste pelos confundidores. Conclusão: Obesidade apresenta pouca ou nenhuma influência na manutenção do EP estático e parece não determinar a ocorrência de quedas em indivíduos acima de 40 anos.

Palavras-chave: Quedas. Equilíbrio Postural. Obesidade.

\section{Introduction}

Postural instability is tightly related to the occurrence of falls $[1,2]$. Currently, it is one of the largest public health problems [3] that cause increasing rates of mortality and morbidity, also leads to immobility situations, loss of independence and hospitalization [4].

Among the numerous factors that could influence the maintenance of postural balance (PB), body weight is suggested to be a strong predictor [5] and being obese is considered a potential contributing factor for falling $[6,7]$. Therefore, high body mass index (BMI) has an association with increased postural sway in obese $[6,8]$, mainly in the medial-lateral (ML) direction for men and anteroposterior (AP) for women [8-10], and occurrence of falls in adults [11]. However, some studies reported no difference between obese and control group regarding the position of the center of pressure (COP) in static PB $[12,13]$ and the dynamic gait stability [14]. Although these previous findings suggest that body weight is responsible for more than $50 \%$ of the variance of COP speed [5], it is not reasonable just to consider this anthropometric variable for explaining the PB in obesity. According to a recent study, the waist circumference presented a strongest association with stabilometric parameters and fall-related outcomes when compared to other anthropometric measurements [15], but other study showed that fat body mass (FBM) is associated to poor balance [16]. Since body mass is insufficient to represent the impact of obesity on static PB, the best anthropometric and body composition variable able to represent the above-mentioned relationship remains to be established. 
Obesity is commonly associated with cardiometabolic comorbidities, lower physical fitness and reduced physical activity [17] and, to our knowledge, there is a lack of investigations about the impact of obesity on $\mathrm{PB}$, free of the confound effect of cardiometabolic risk. Since falling can be determined by the interaction between chronic predisposing diseases and impairments [18], there is a need to consider these other variables to clarify the association between static PB and obesity.

We hypothesized that obesity has little or no influence on PB when considering the confound effect of cardiometabolic comorbidities and physical fitness. Therefore, the aim of this study was to evaluate the effects of obesity on static PB in asymptomatic adults by using and comparing anthropometric measures and fat body mass (FBM). Secondarily, the study was designed to evaluate the association of obesity with the occurrence of falls in a subsample of middle-aged and older adults.

\section{Method}

Participants

We conducted a cross-sectional study with eligible participants from Epidemiological Study on Human Movement (EPIMOV Study). Briefly, the EPIMOV Study is an epidemiological study with the main objective of determine the longitudinal association shown by sedentary behavior and physical inactivity related to development of hypokinetic diseases [19]. The Research Ethics Committee of human beings approved the EPIMOV study (\# 186.796). In addition, all participants provided written informed consent.

The volunteers were recruited by announcements in social medias, in regional universities, in magazines and local journals. The EPIMOV Study exclusion criteria are previous diagnosis of cardiovascular, respiratory or musculoskeletal disease and/or any health problem that might interfere the ability to undertake physical exercise. All EPIMOV Study's participants were eligible for this study. For the present study, we selected those with $\geq 40$ years.

Since the proportion of fallers among middle-aged and older adults is similar and the rate of falls and fallrelated injuries increases from 25 years and above [2], it is reasonable to investigate the determinants of postural balance in middle-aged subjects.
Clinical evaluation

Before starting the evaluation, we questioned the volunteers about previous health problems, regular use of medication and risk factors for cardiovascular diseases, such as age, family history, smoking, hypertension, dyslipidemia, and diabetes mellitus. Then, they answered the Physical Activity Readiness Questionnaire for identifying possible contraindications of performing exercise [20].

\section{Anthropometric and body composition}

We collected height $(\mathrm{m})$ and body mass $(\mathrm{kg})$ by using a digital balance with a stadiometer $\left(\right.$ Toledo $^{\circledR}$, São Paulo, Brazil). Circumferences of hip and waist were measured according to standardized techniques [21]. Then, we calculated BMI $\left(\mathrm{kg} / \mathrm{m}^{2}\right)$, waist-to-hip ratio and waist-to-height ratio.

We assessed body composition by using bioelectrical impedance (310e BIODYNAMICS, Detroit, EUA) at ambient temperature. The impedance and the reactance were collected from the subject in the supine position with arms and legs in $30^{\circ}$ and $45^{\circ}$ of abduction, as described previously $[22,23]$. Using the equation developed for healthy subjects [24], we calculated lean body mass (LBM) and FBM. LBM and FBM were expressed as percentage and absolute value. We instructed volunteers to avoid ingesting any liquid or food for prior 4 hours and avoid practicing physical exercises for at least 12 hours before the test.

\section{Cardiorespiratory fitness}

We performed a cardiopulmonary exercise testing (CEPT) on a treadmill (ATL, Inbrasport, Porto Alegre, Brazil) using a ramp protocol with individualized increases in velocity and inclination until exhaustion [25]. Oxygen uptake (V'O2), carbon dioxide production ( $\left.V^{\prime} \mathrm{CO} 2\right)$, and minute ventilation ( $\left.\mathrm{V}^{\prime} \mathrm{E}\right)$ were monitored throughout the test using a gas analyzer (Quark PFT, Cosmed, Pavona di Albano, Italy). The heart rate (HR) was continuously monitored during the CPET by means of a 12 lead ECG. The average value of the V'O2 (mL/min/ $\mathrm{kg}$ ) during the last $15 \mathrm{~s}$ of the CPET was representative of the peak V'O2 (i.e., cardiorespiratory fitness) [25]. 
Physical activity level

We assessed the level of physical activity in daily life (PADL) using triaxial accelerometers (ActiGraph, MTI, Pensacola, FL) previously validated [26, 27]. All participants were carefully instructed regarding the use of the aforementioned devices. They performed the evaluation during a week after the first-day test in this study. We analyzed only the data of participants who used the accelerometer for at least four valid days (e.g., 10 wakening hours of monitoring). The minimum PADL was considered as 30 minutes daily of MVPA for at least 5 days per week, as recommended [28]. Participants who did not reach this level were considered as physically inactive.

\section{Postural balance}

We evaluated PB using the kinetic displacement of the COP on a force platform (BIOMEC 400, EMGSystem, Brazil) $[29,30]$. The frequency of data acquisition was recorded at $100 \mathrm{~Hz}$ and filtered using a low-pass cut-off of $0.5 \mathrm{~Hz}$. Participants were evaluated with arms held alongside the body in bipedal stance (BS) and in semitandem stance (ST) for 30 seconds in each test. First, with eyes fixating a reference point located at eyes level $11 \mathrm{~m}$ in front of them) and, then, with eyes closed. Volunteers performed one trial for each condition. Body sway was measured along AP and ML directions. We recorded average amplitude, median frequency, and COP area for further analysis. Average amplitude $(\mathrm{cm})$ was obtained through variance values of body sway on directions AP and ML. The area of the ellipse was obtained by covering the COP sway trajectory. The amplitude of displacement is a reliable parameter and widely used to evaluate postural deficits, especially in the ML direction [29].

\section{Muscle function}

We evaluated muscle function through isokinetic dynamometry (Biodex, Lumex Inc., Ronkonkoma, NY, EUA) as previous described [31]. In seated position, the upper body and the assessed lower limb were completely fixed by strips. Wealigned the mechanical axis of rotation of the device to the rotational axis of the assessed joint. After a trial session, we assessed the peak torque of knee extension (PT, $\mathrm{Nm}$ ) by five movements at $60 \% / \mathrm{s}$. The greater value was selected for further analysis. We applied these tests to quadriceps muscle under vehement verbal encouragement.
History of falls

Participants were inquired about the occurrence of falls in the 12 months prior to the study. The participants answered two questions: "Did you fall in the last 12 months?". If the answer was yes, we also inquired how many falls did they suffer in this period. They were stratified as fallers, who had one or more falls within 12 months prior to the study, and non-fallers, who had none fall within the period. Fall was defined as any unplanned and unexpected event that results in body contact to the surface [3].

\section{Statistical Analysis}

The statistical analysis was performed using SPSS, version 23 (SPSS Inc., Chicago, IL, EUA). We present data as means \pm SD and $95 \%$ confidence interval. Initially, we evaluated the Pearson or Spearman coefficient of correlations for testing the bivariate relationship between indices of obesity (BMI, FBM, waist-to-hip ratio, and waist-to-height ratio) and the PB variables. Then, we performed several multiple linear regression models to confirm whether or not the indices of obesity are independent predictors of $\mathrm{PB}$.

For identifying the best index of obesity able to predict $\mathrm{PB}$ as well as for comparing the influence of the severity of obesity on PB, we stratified the whole sample according to the quartiles of BMI, waist-to-hip ratio, waist-to-height ratio and percentage of FBM. We compared all the force platform variables using the MANOVA analysis, after normalization of the data using logarithms. We presented the significant differences by means of box plots.

As for the associations with the occurrence of falls, we dichotomized the participants according to the medians of the above-mentioned indices of obesity. Lastly, we carried out four multiple logistic regressions using the history of falls ( $0=$ no falls, $1=1$ or more falls) as the outcome and the categorized indices of obesity as the main predictors.

All the multivariate analysis were adjusted for age (years), sex, peak V'O2 (ml/min/kg), LBM (kg), PT (Nm) and the presence of diabetes, dyslipidemia, physical inactivity (assessed by triaxial accelerometers), hypertension, and smoking. The sample size was estimated based on the number of variables included in the multivariate model and the minimum number of observations required, indicating at least 165 subjects for elaborating a model containing these variables. The level of statistical significance was set at $\mathrm{p}<0.05$. 


\section{Results}

624 participants (aged 18 to 82 years, 260 men) from EPIMOV Study were considered eligible. The sample was composed mainly by women with prevalence of risk factors for cardiovascular diseases as follows: hypertension (19.9\%), diabetes (9.3\%), dyslipidemia (30.9\%), smoking (11\%) and physical inactivity (27\%).

For women, the defined quartiles of BMI, waist-tohip ratio, waist-to-height ratio and percentage of FBM were, respectively, as follows: $23.72,28.60$ and 34.13 $\mathrm{kg} / \mathrm{m} 2 ; 0.48,0.56$ and $0.64 ; 0.77,0.83$ and 0.89 ; and 29.6, 36.6 and $41.3 \%$. And for men, the quartiles were 24.25, 27.25 and $30.47 \mathrm{~kg} / \mathrm{m} 2$ for BMI, $0.47,0.52$ and 0.59 for waist-to-hip ratio, $0.84,0.89$ and 0.96 for waistto-height ratio, and $17.5,23.4$ and $28.1 \%$ for FBM.

As expected, the fourth quartile of BMI has the greater values for all variables, except for PT and peak V'O2, indicating lower physical fitness among severely obese subjects (Table 1 ).

The logistic regression analysis showed that obesity was not related to the occurrence of falls since the odds ratio values became non-significantfor all these indices of obesity after adjustment for the main confounders (Table 2).

We found weak to moderate bivariate correlations between the indices of obesity and the static PB. Most of then became non-significant after multiple regression analysis adjusted for the main confounders as can be seen in the Table 3.

We observed some significant differences between first and fourth quartiles of the indices of obesity, especially using \%FBM (Figure 1) and for body sway on ML direction (Table 4).
Table 1 - General characteristics of the studied sample stratified according to the quartiles of the body mass index

\begin{tabular}{|c|c|c|c|c|}
\hline & $\begin{array}{c}\text { Quartile } 1 \\
N=156\end{array}$ & $\begin{array}{l}\text { Quartile 2 } \\
N=156\end{array}$ & $\begin{array}{c}\text { Quartile } 3 \\
N=157\end{array}$ & $\begin{array}{l}\text { Quartile } 4 \\
N=155\end{array}$ \\
\hline Age (years) & $38 \pm 15$ & $42 \pm 15^{a}$ & $50 \pm 13^{a b}$ & $51 \pm 12^{\mathrm{ab}}$ \\
\hline Males/females & $62 / 94$ & $68 / 88$ & $65 / 92$ & $65 / 90$ \\
\hline Weight (kg) & $58.3 \pm 7.8$ & $70.8 \pm 9.0^{a}$ & $80.5 \pm 10.5^{\mathrm{ab}}$ & $97.7 \pm 14.3^{\mathrm{abc}}$ \\
\hline Height (m) & $1.63 \pm 0.09$ & $1.64 \pm 0.09$ & $1.62 \pm 0.10$ & $1.61 \pm 0.09$ \\
\hline $\begin{array}{l}\text { Body mass } \\
\text { index (kg/m2) }\end{array}$ & $21.8 \pm 1.6$ & $25.9 \pm 1.1^{\mathrm{a}}$ & $30.2 \pm 1.45^{\mathrm{ab}}$ & $37.6 \pm 4.4^{\mathrm{abc}}$ \\
\hline Waist (cm) & $73.4 \pm 7.0$ & $84.3 \pm 7.1^{\mathrm{a}}$ & $94.9 \pm 9.1^{\mathrm{ab}}$ & $109.8 \pm 11.5^{\mathrm{abc}}$ \\
\hline Hip (cm) & $92.3 \pm 4.8$ & $99.9 \pm 5.1^{\mathrm{a}}$ & $105.9 \pm 7.4^{\mathrm{ab}}$ & $122.0 \pm 10.8^{\mathrm{abc}}$ \\
\hline $\begin{array}{l}\text { Waist-to- } \\
\text { hip ratio }\end{array}$ & $0.80 \pm 0.08$ & $0.85 \pm 0.08^{a}$ & $0.90 \pm 0.099^{2 b}$ & $0.90 \pm 0.08^{\mathrm{ab}}$ \\
\hline $\begin{array}{l}\text { Waist-to- } \\
\text { height ratio }\end{array}$ & $0.45 \pm 0.05$ & $0.51 \pm 0.04^{a}$ & $0.58 \pm 0.06^{\mathrm{ab}}$ & $0.68 \pm 0.08^{\mathrm{abc}}$ \\
\hline $\begin{array}{l}\text { Lean body } \\
\text { mass }(\mathbf{k g})\end{array}$ & $44.7 \pm 9.2$ & $52.1 \pm 10.4^{a}$ & $54.0 \pm 11.2^{\mathrm{a}}$ & $57.8 \pm 10.4^{\mathrm{abc}}$ \\
\hline $\begin{array}{l}\text { Lean body } \\
\text { mass }(\%)\end{array}$ & $75.9 \pm 7.1^{\mathrm{bcd}}$ & $72.6 \pm 6.9^{\mathrm{cd}}$ & $66.5 \pm 7.4^{d}$ & $58.7 \pm 6.8$ \\
\hline $\begin{array}{l}\text { Fat body } \\
\text { mass (kg) }\end{array}$ & $13.6 \pm 3.6$ & $19.4 \pm 5.6^{b}$ & $26.6 \pm 5.5^{\mathrm{ab}}$ & $40.2 \pm 8.4^{a b c}$ \\
\hline $\begin{array}{l}\text { Fat body } \\
\text { mass (\%) }\end{array}$ & 23.8 & $27.4 \pm 7.0^{a}$ & $33.3^{\mathrm{ab}}$ & $40.9 \pm 5.3 \mathrm{abc}$ \\
\hline $\begin{array}{l}\text { Peak torque } \\
\text { of knee } \\
\text { extension } \\
\text { (NM) }\end{array}$ & $127 \pm 51$ & $140 \pm 55$ & $132 \pm 61$ & $123 \pm 49$ \\
\hline $\begin{array}{l}\text { Peak oxygen } \\
\text { uptake } \\
(\mathrm{mL} / \mathrm{min} / \mathrm{kg})\end{array}$ & $36.5 \pm 10.7$ & $28.9 \pm 10.5^{a}$ & $26.8 \pm 8.6^{\mathrm{ab}}$ & $20.8 \pm 5.1^{1 \mathrm{abc}}$ \\
\hline $\begin{array}{l}\text { Number of } \\
\text { fallers (\%) }\end{array}$ & $6(3.8)$ & $9(5.8)$ & 17 (10.8) & $28(18.1)^{\mathrm{ab}}$ \\
\hline
\end{tabular}

Table 2 - Associations between severity of obesity and the occurrence of falls in the studied sample over the age of 40 years $(n=387)$

\begin{tabular}{|c|c|c|c|c|c|c|}
\hline & \multicolumn{3}{|c|}{ Unadjusted odds ratios and $95 \%$ confidence intervals } & \multicolumn{3}{|c|}{$\begin{array}{l}\text { Adjusted odds ratios and } 95 \% \text { confidence } \\
\text { intervals }\end{array}$} \\
\hline & \multirow[b]{2}{*}{ OR } & \multicolumn{2}{|c|}{$95 \%$ confidence interval } & \multirow[b]{2}{*}{ OR } & \multicolumn{2}{|c|}{ 95\%confidence interval } \\
\hline & & Lower limit & Upper limit & & Lower limit & Upper limit \\
\hline Body mass index & $3.75^{\star}$ & 2.13 & 6.60 & 1.43 & 0.52 & 3.90 \\
\hline Fat body mass & $4.13^{\star}$ & 2.19 & 7.81 & 1.47 & 0.54 & 4.04 \\
\hline Waist-to-hip ratio & $2.27^{\star}$ & 1.23 & 4.17 & 1.57 & 0.59 & 4.19 \\
\hline Waist-to-height ratio & $3.41^{*}$ & 1.40 & 8.25 & 2.09 & 0.64 & 6.80 \\
\hline
\end{tabular}

Note: ${ }^{\star} \mathrm{p}<0.05$. Predictors were binned according to the median values. 

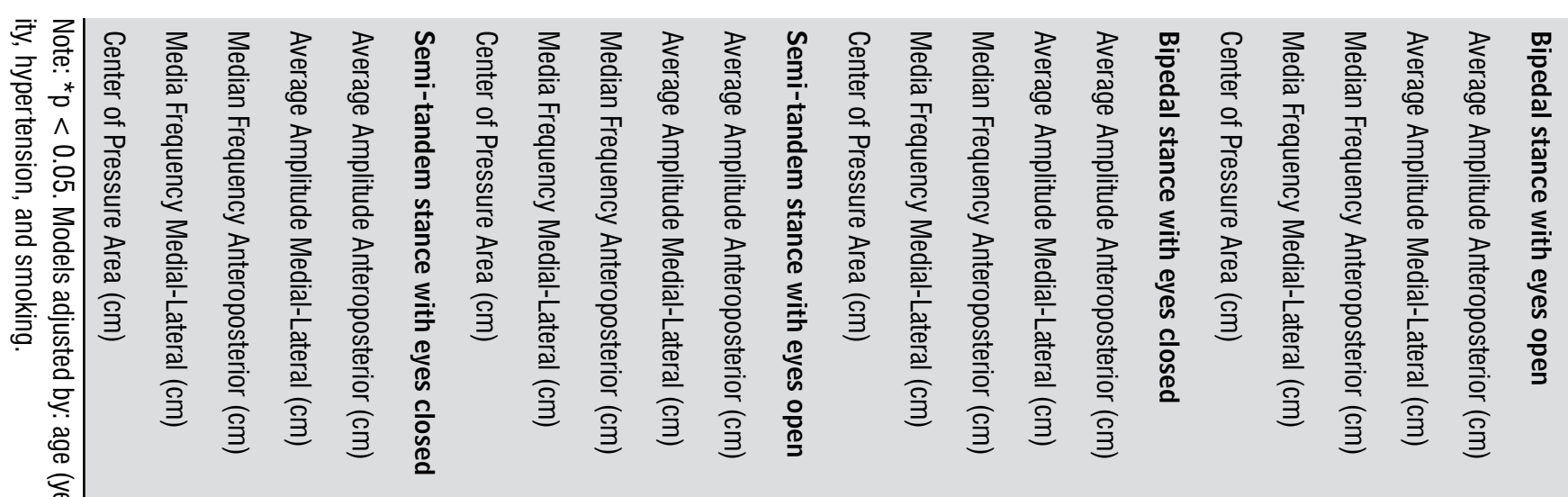

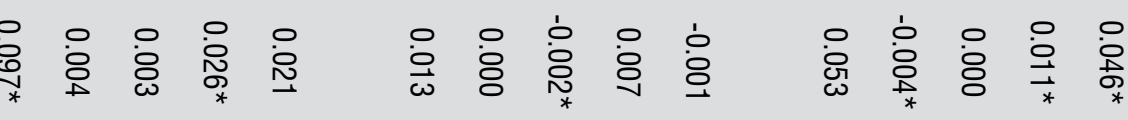

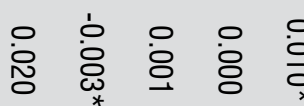

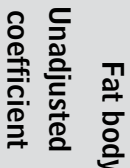

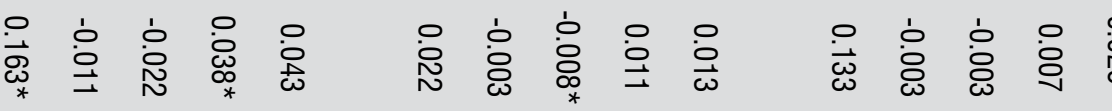
它

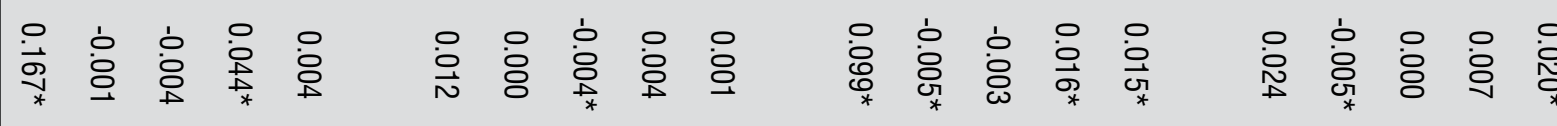

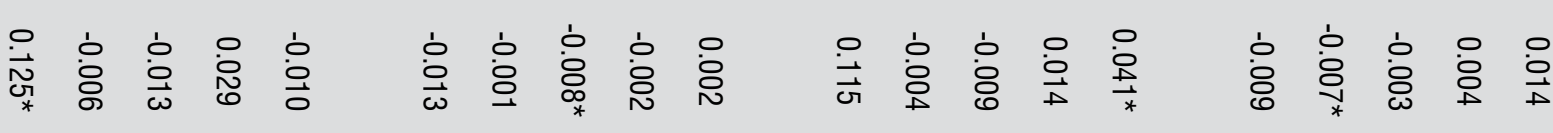

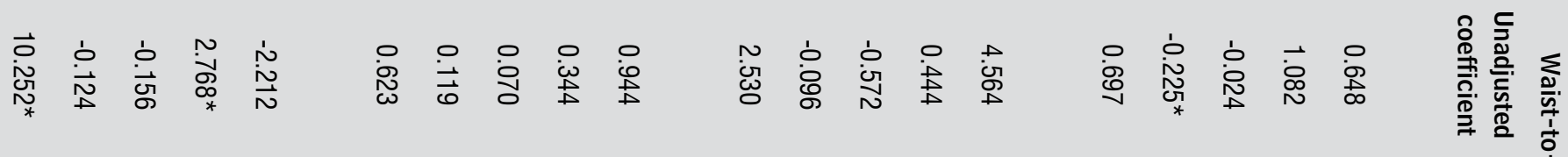




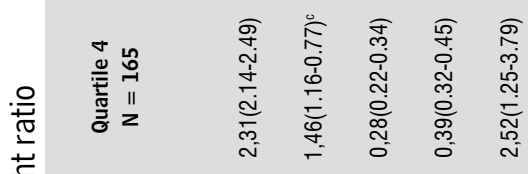

亭

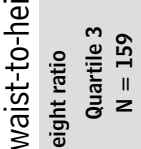

它

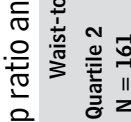

魹

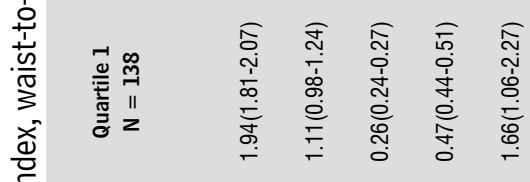

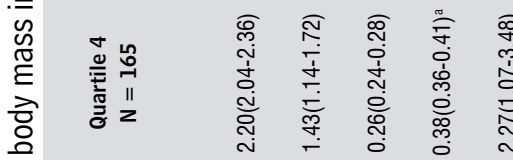

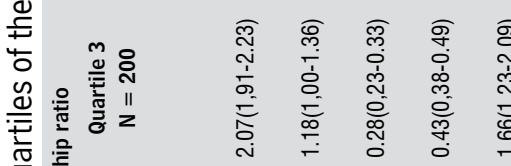

至

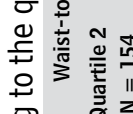

읗

论

垔

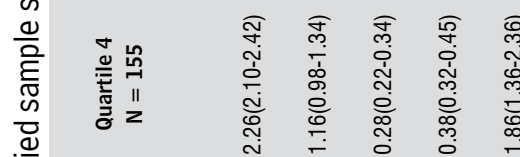

$\frac{\text { 重 }}{\text { 总 }}$

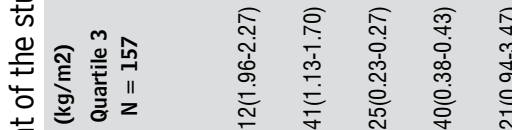

बे

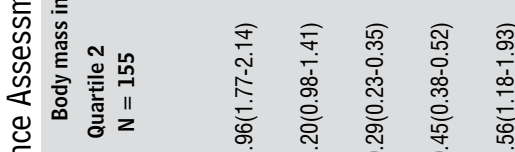

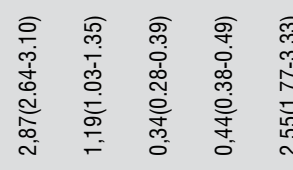

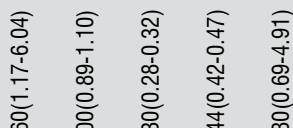

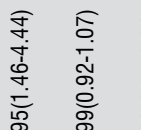

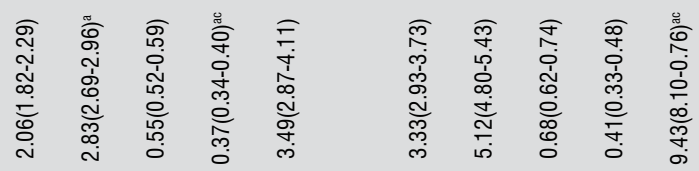

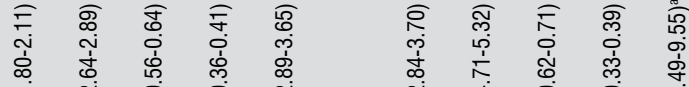

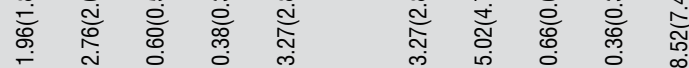
ब,

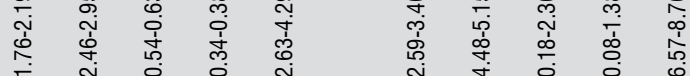
离

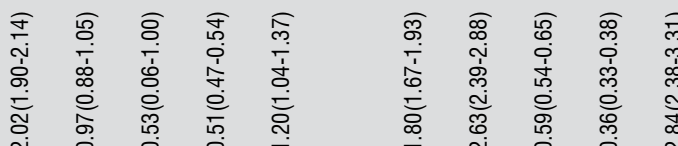

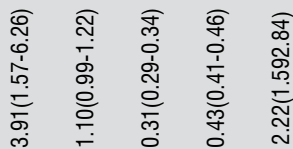

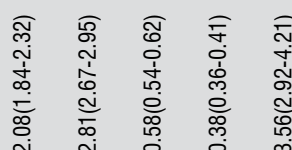

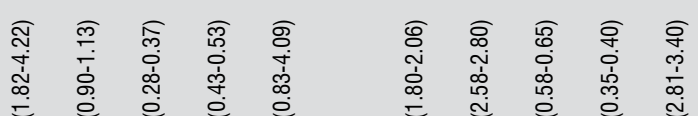

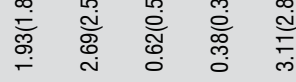

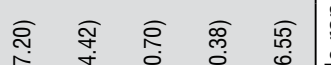

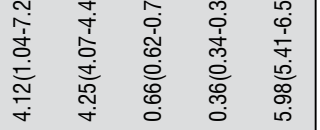
๙

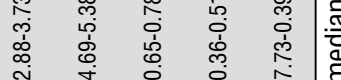

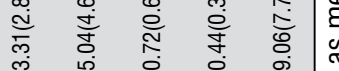

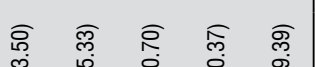

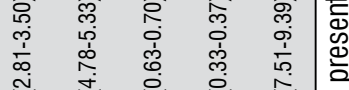

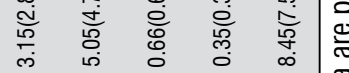

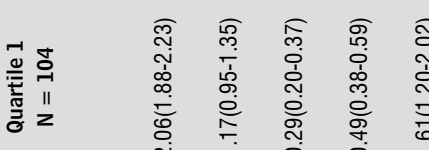

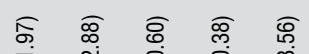

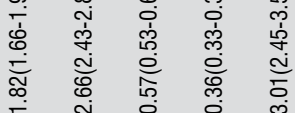

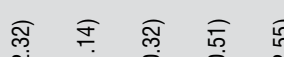

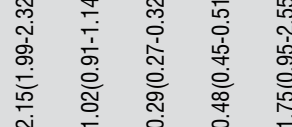

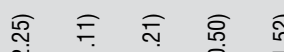
\&े 产

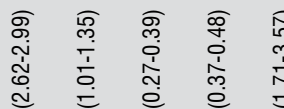

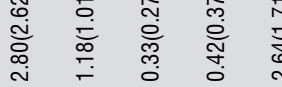

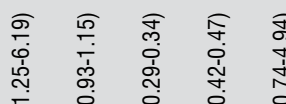
觉

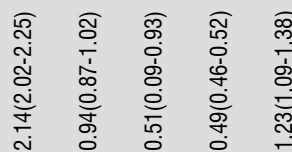

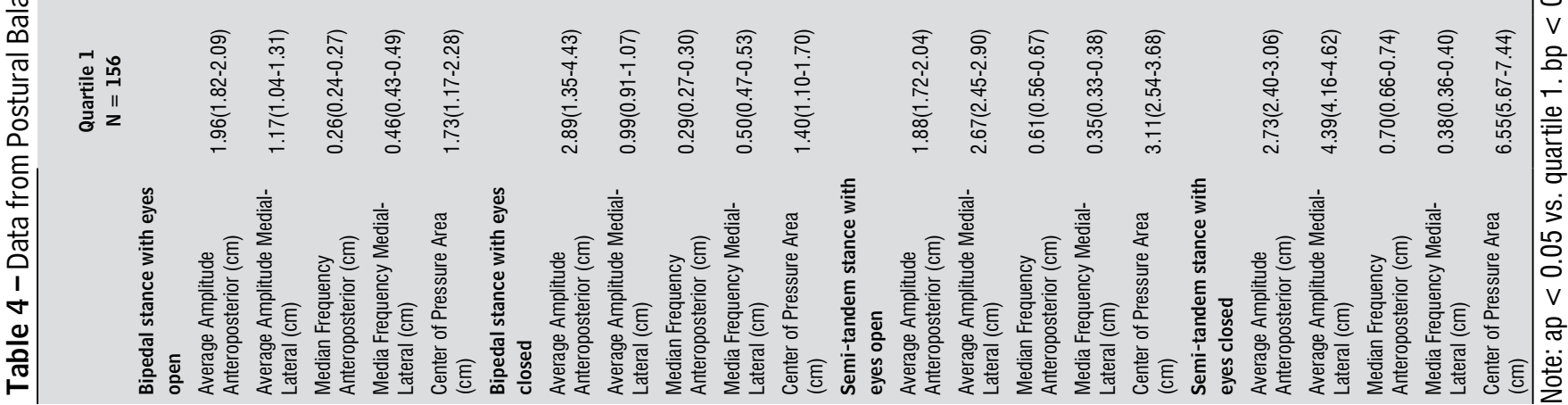

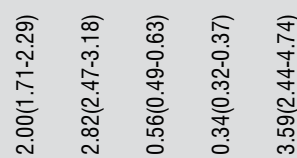

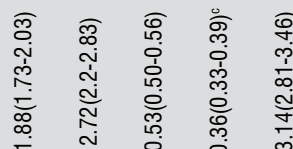

ల్ల ब ब্्ब

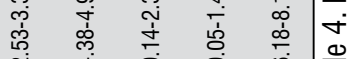
离

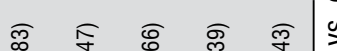

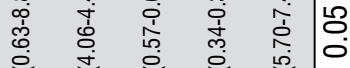

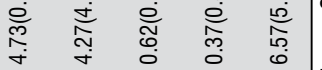

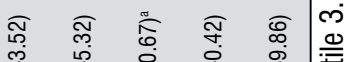

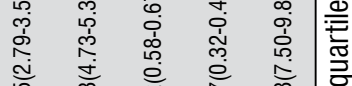

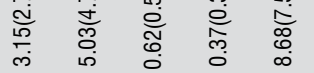

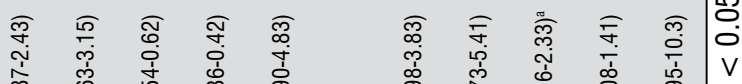

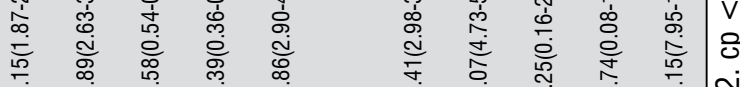
๑ ब

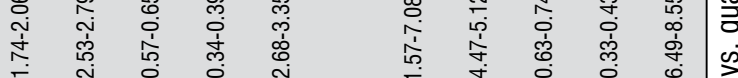

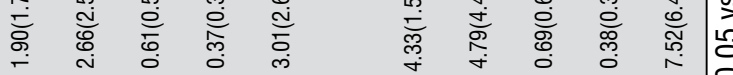




\section{Discussion}

We found in the present study only a little influence on the severity of the obesity on the PB. However, these changes do not seem to be an important feature for increasing occurrence of falls among subjects over 40 years old.

Hue et al. [5] showed that the body weight is a strong predictor of PB using a stepwise multiple regression analysis adjusted for height, foot length, and age. Nevertheless, only 59 subjects were enrolled (BMI $=35.2 \pm 11.7 \mathrm{~kg} / \mathrm{m}^{2}$ and age $\left.=40.5 \pm 9.5 \mathrm{yr}\right)$. The differ ences between our results and Hue et al. [5] results may be attributed, firstly to the larger proportion of severely obese adults enrolled in the present study and, secondly, to the methodological differences regarding frequency of acquisition the data on the force platform $(200 \mathrm{~Hz})$ and confounders adjusted in the regression models.

As obtained in the present study, our bivariate and multivariate models shown that obesity presents justa few correlations with $\mathrm{PB}$, and most of them became nonsignificant after adjustments (Table 2). Also, the fourth quartile of BMI, waist-to-hip ratio, waist-to-height ratio, and \%FBM showed significant worse PB. We found that the great severity of obesity and high central obesity presented the worse PB (Figure 1 and Table 3). Despite the distinct interpretation, our results are in agreement from those obtained in the study of Singh et al. [7], which describes that the extremely obese presented poor balance when compared to non-obese. According to previous studies [32-34], the visceral obesity and android body fat distribution, as well as age-related sarcopenia in quadriceps muscle, are related to PB. Also, our findings were consistent with the previous literature, showing the influence of obesity on PB only in more severe obese subjects and in situations with greater instability (e.g., ST and eyes closed) [7, 12, 35-37]. This may be explained by the distribution of FBM [15-17, 32, 33, 38] and mechanical constraints due to severe obesity $[8,35,39]$, but, most of all, we suggested that is related to decreased of muscular strength $[34,35]$ and possible related to fatigue [7], presence of comorbidities [18, 40-43] and poor physical fitness and PADL [17].

From an artificial increase in body weight [44], it has been observed that the weight increase had a negative effect on maintaining PB standing upright. However, the aforementioned results should be analyzed with caution, since must be considered the distribution of excess of weight [17] and postural changes resulting from this increase, as well as the physical fitness and PADL. Similarly, loss of body weight, in turn, improves postural stability by effects on the alignment of the whole body and ameliorate the capabilities of the postural control system. This beneficial effect of loss of body weight is tightly related to the magnitude of the weight loss and due to the reduced contact of the plantar area [45]. Moreover, the weight gain is gradual and often centered in abdominal region as well as observed in pregnancy for example. Although women had their weight in the anterior abdominal region increased during pregnancy, no significant differences have been found static PB when comparing early pregnancy, advanced pregnancy, and at 2 months and 6 months postpartum [46]. These results may be attributed to postural adaptive changes assumed by those women and also reported that the decreased static PB occurs under visual deprivation condition [46], which is consistent with our findings (e.g. worse PB with eyes closed) and may represent a plausible and possible reason for our main results.

Morbid obesity may lead to the deficit of PB and greater effect of the trunk in the ML displacement [8, 47]. After specific $P B$ training and weight loss program, $\mathrm{PB}$ can be improved $[45,48]$. It is imperative to assess individual differences in regional distribution of body fat [15-17], which may be subject to genetic factors, diet, and PADL [17]. The sedentary to active lifestyle transition may lead to positive adaptations and cardioprotection that can turn the body more capable of performing exercise [17], as well as to maintain PB. Also, strength, power and aerobic training can improve balance and functional performance $[48,49]$. The maintenance of cardiorespiratory fitness through physical activity and non-smoking is equally important, which the opposite such as a restrictive pattern on spirometry is significantly associated with increased COP area [19].

We observed a significant correlation between lower limb isokinetic muscle function and AP and ML displacement of the COP, especially in more difficult tasks (e.g., the ST stance with eyes closed). These results have already been described previously [35]. These findings were meaningful when to consider aging since maximal concentric lower extremity strength is reduced, especially decreased of maximal strength of the quadriceps from the fifth decade and its correlates with significant reductions in activities of lower extremity muscles [48]. 
Fat body mass (\%)

Eyes Open

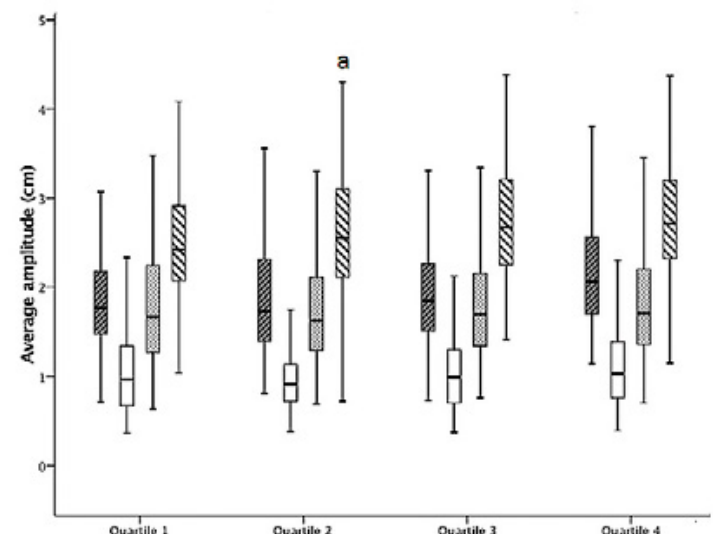
Anterior-posterior (bipedal stance)
Medial-lateral (bipedal stance)

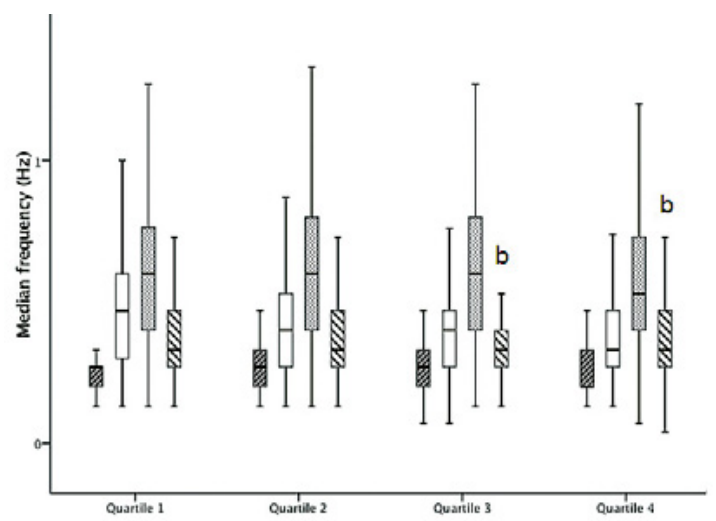

Anterior-posterior (bipedal stance)
Medial-lateral (bipedal stance) Medial-lateral (semi-tandem)

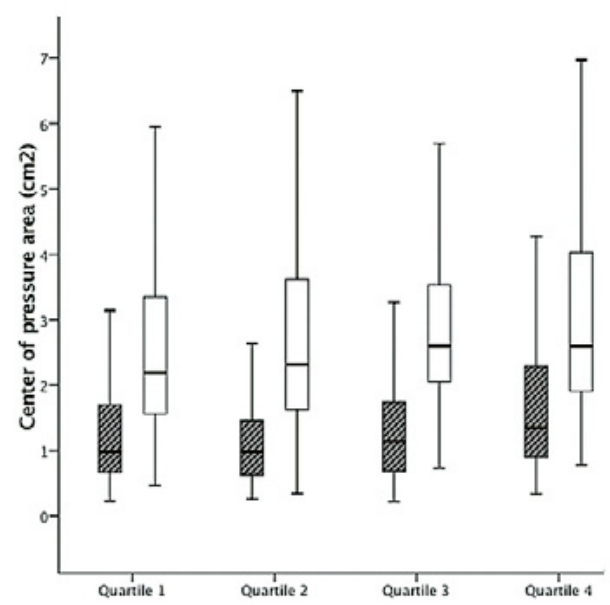

Bipedal stance Semi-tandem
Fat body mass (\%)

Eyes Closed

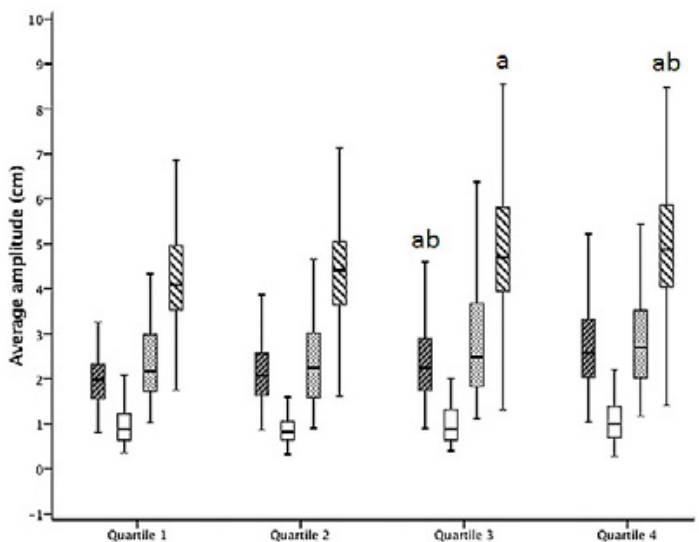

Anterior-posterior (bipedal stance)
Medial-lateral (bipedal stance)

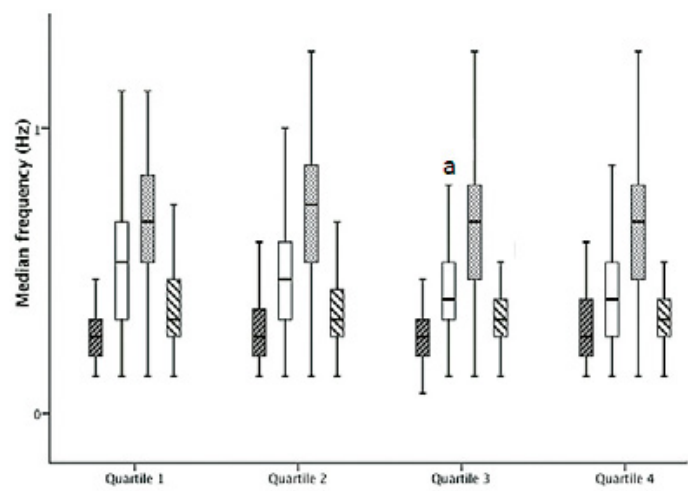

Anterior-posterior (bipedal stance) Anterior-posterior (semi-tandem)

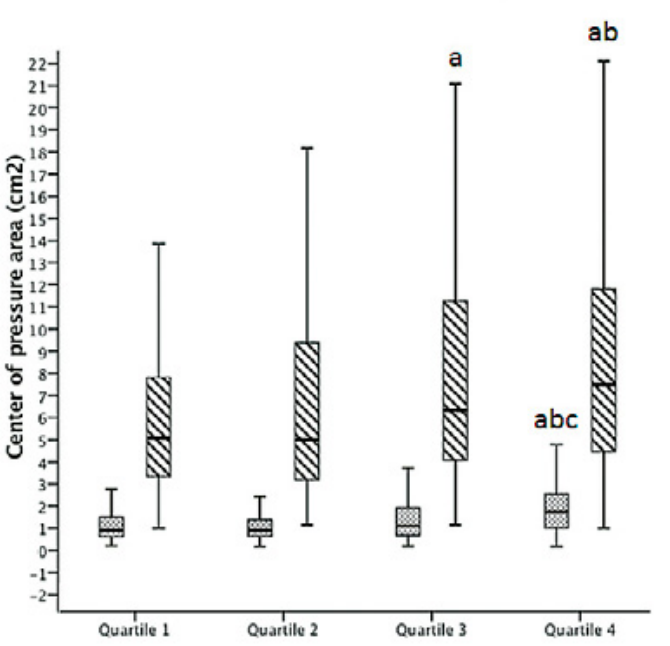

Bipedal stance

Figure 1 - Postural balance on the force platform in participants stratified according to the quartiles of the fat body mass (\%). Note: ap $<0.05$ vs. quartile 1 . ${ }^{\text {bp }}<0.05$ vs. quartile 2 . ${ }^{c p}<0.05$ vs. quartile 3 . 
Accompanied by those changes, the decreased PADL can aggravate and even accelerate the loss of strength, becoming an important feature in the risk of falling and also generating fear of falling [50]. It is known that men who had recurrent falls presented lower PADL, lower amount of moderate-to-vigorous physical activity and more sedentary behavior when comparing with healthy men [50], which suggest lower exercise self-efficacy and more mobility difficulties.

Regarding the postural control system, the reduced plantar sensitivity alone could not incur significant PB disorders [51]. A study with individuals with type 2 diabetes reported that peripheral neuropathies had an independent influence on PB, both in eyes open and closed situations as well as on different surfaces [41]. This influence was greater with increasing BMI above 30 $\mathrm{kg} / \mathrm{m} 2$ and in men. Additionally, the use of medication and presence of hypertension, diabetes, and dyslipidemia can also negatively influence balance by effects on the sensory and motor components of $\mathrm{PB}[18,40]$. Thus, our results reinforce the previous findings [41] regarding the independent associations of obesity with sex and cardiovascular risk factors and hence the occurrence of falls. Di Iorio et al. [52] found that the obesity was poorly associated with worse $\mathrm{PB}$ while the cumulative presence of cardiovascular risk factors lead to poor $\mathrm{PB}$ in elderly subjects.

Commonly used to diagnose obesity, the BMI cannot reflect important differences, when considering elderly or normal-weighted and physically active subjects $[15-17,53]$. Our results demonstrate that, when establishing PB and body weight association, the most clinically relevant variable is the \%FBM. Our results are in accordance with reported by Meng et al. [53]. A range of 2 to 3 times in visceral adiposity for each BMI classification may occur [17], which limits its applicability and justifies the results presented here. Thus, the use of body composition variables, measured by bioelectrical impedance, might be more suitable for identifying obesity-related PB changes (Figure 1).

Some limitations of the present study should be considered. The cross-sectional design of the study, absence of assessment of dynamic PB, and the greater number of female participants are the main limitations. However, the participants enrolled in EPIMOV Study present prevalence of comorbidity similar to describe for our population. Despite the discrepancies related to sex, our sample size was enough and the multivariate analyzes were carefully adjusted by sex as well as by the other main confounders. Thus, we are confident about the generalizability of the results presented here. On the other hand, our study has strengths. The most important were the adjustment for objective and precise measures of physical activity and fitness, such as PADL by a triaxial accelerometer, isokinetic muscle function and peak V'O2 in CPET.

We can conclude that obesity per se presents little influence on maintaining static PB. Additionally, the obesity seems not to determine the occurrence of falls among subjects over 40 years old.

\section{References}

1. Peel NM. Epidemiology of Falls in Older Age. Can J Aging. 2011;30(1):7-19.

2. Verma SK, Willetts JL, Corns HL, Marucci-Wellman HR, Lombardi DA, Courtney TK. Falls and Fall-Related Injuries among Community-Dwelling Adults in the United States. PLoSOne. 2016;11(3):e0150939.

3. Shumway-Cook A, Brauer S, Woollacott M. Predicting the probability for falls in community-dwelling older adults using the Timed Up \& Go Test. Phys Ther. 2000;80(9):896-903.

4. Rubenstein LZ. Falls in older people: epidemiology, risk factors and strategies for prevention. Age Ageing. 2006;35(Suppl 2):ii37-ii41.

5. Hue O, Simoneau M, Marcotte J, Berrigan F, Doré J, Marceau P, et al. Body weight is a strong predictor of postural stability. Gait Posture. 2007;26(1):32-8.

6. Dutil M, Handrigan GA, Corbeil P, Cantin V, Simoneau $\mathrm{M}$, Teasdale N. The impact of obesity on balance control in community-dwelling older women. Age (Dordr). 2013;35(3):883-90.

7. Singh D, Park W, Levy MS, Jung ES. The effects of obesity and standing time on postural sway during prolonged quiet standing. Ergonomics. 2009;52(8):977-86.

8. McGraw B, McClenaghan BA, Williams HG, Dickerson J, Ward DS. Gait and postural stability in obese and nonobese prepubertal boys. Arch Phys Med Rehabil. 2000;81(4):484-9. 
9. Menegoni F, Tacchini E, Bigoni M, Vismara L, Priano L, Galli M, et al. Mechanisms underlying center of pressure displacements in obese subjects during quiet stance. J Neuroeng Rehabil. 2011;8:20.

10. Menegoni F, Galli M, Tacchini E, Vismara L, Cavigioli M, Capodaglio P. Gender-specific Effect of Obesity on Balance. Obesity. 2009;17(10):1951-6.

11. Herrera-Rangel AB, Aranda-Moreno C, Mantilla-Ochoa T, Zainos-Saucedo L, Jáuregui-Renaud K. Influence of the body mass index on the occurrence of falls in patients with type 2 diabetes mellitus. Obes Res Clin Pract. 2015;9(5):522-6.

12. Colné P, Frelut ML, Pérès G, Thoumie P. Postural control in obese adolescents assessed by limits of stability and gait initiation. Gait Posture. 2008;28(1):164-9.

13. Pereira C, Silva RAD, Oliveira MR, Souza RDN, Borges RJ, Vieira ER. Effect of body mass index and fat mass on balance force platform measurements during a one-legged stance in older adults. Aging Clin Exp Res. 2018;30(5):441-7.

14. Liu ZQ Yang F. Obesity May Not Induce Dynamic Stability Disadvantage during Overground Walking among Young Adults. PLoSOne. 2017; 12(1):e0169766.

15. Neri SGR, Gadelha AB, David AC, Ferreira AP, Safons MP, Tiedemann A, et al. The Association Between Body Adiposity Measures, Postural Balance, Fear of Falling, and Fall Risk in Older Community-Dwelling Women. J Geriatr Phys Ther. 2017;42(3):E94-E100.

16. Verma SK, Willetts JL, Corns HL, Marucci-Wellman HR, Lombardi DA, Courtney TK. Adiposity and postural balance control: correlations between bioelectrical impedance and stabilometric signals in elderly Brazilian women. Clinics (Sao Paulo). 2011;66(9):1513-8.

17. Després JP. Obesity and cardiovascular disease: weight loss is not the only target. Can J Cardiol. 2015;31(2):216-22.

18. Tinetti ME, Kumar C. The patient who falls: "It's always a trade-off". JAMA. 2010;303(3):258-66.

19. Sperandio EF, Arantes RL, Matheus AC, Silva RP, Lauria VT, Romiti M, et al. Restrictive pattern on spirometry: association with cardiovascular risk and level of physical activity in asymptomatic adults. J Bras Pneumol. 2016;42(1):22-8.
20. Thomas S, Reading J, Shephard RJ. Revision of the Physical Activity Readiness Questionnaire (PAR-Q). Can J Sport Sci. 1992;17(4):338-45.

21. Center for Health Statistics. NHANES National Youth Fitness Survey (NYFS). Body Measures Procedures Manual: 2012.

22. Kyle UG, Bosaeus I, De Lorenzo AD, Deurenberg P, Elia M, Gómez JM, et al. Bioelectrical impedance analysis-part I: review of principles and methods. Clin Nutr. 2004;23(5):1226-43.

23. Kyle UG, Bosaeus I, De Lorenzo AD, Deurenberg P, Elia M, Gómez JM, et al. Bioelectrical impedance analysis-part II: utilization in clinical practice. Clin Nutr. 2004;23(6):1430-53.

24. Kyle UG, Genton L, Karsegard L, Slosman DO, Pichard C. Single prediction equation for bioelectrical impedance analysis in adults aged 20-94 years. Nutrition. 2001;17(3):248-53.

25. Wasserman K, Hansen JE, Sue DY, Stringer WW, Sietsema KE, Sun XG, et al. Principles of Exercise Testing and Interpretation. Philadelphia: Lippincott Williams \& Wilkins; 2011.592 p.

26. Troiano RP, Berrigan D, Dodd KW, Louise MC, Timothy T, Mcdowell M. Physical activity in the United States measured by accelerometer. Med Sci Sports Exerc. 2008;40(1):181-8.

27. Brooks AG, Gunn SM, Withers RT, Gore CJ, Plummer JL. Predicting Walking METs and Energy Expenditure from Speed or Accelerometry. Med Sci Sport Exerc. 2005;37(7):1216-23.

28. American College of Sports Medicine Position Stand. The recommended quantity and quality of exercise for developing and maintaining cardiorespiratory and muscular fitness, and flexibility in healthy adults. Med Sci Sports Exerc. 1998;30(6):975-91.

29. Paillard T, Noé F. Techniques and Methods for Testing the Postural Function in Healthy and Pathological Subjects. Biomed Res Int. 2015;2015:891390. 
30. Toledo DR, Barela JA. Sensory and motor differences between young and older adults: somatosensory contribution to postural control. Rev Bras Fisioter. 2010;14(3):267-75.

31. Neder JA, Nery LE, Shinzato GT, Andrade MS, Peres C, Silva AC. Reference values for concentric knee isokinetic strength and power in nonathletic men and women from 20 to 80 years old. J Orthop Sports Phys Ther. 1999;29(2):116-26.

32. Hita-Contreras F, Martínez-Amat A, Lomas-Vega R, Álvarez P, Mendoza N, Romero-Franco N, et al. Relationship of body mass index and body fat distribution with postural balance and risk of falls in Spanish postmenopausal women. Menopause J North Am Menopause Soc. 2012;20(2):202-8.

33. Cieślińska-Świder J, Furmanek MP, Błaszczyk JW. The influence of adipose tissue location on postural control. J Biomech. 2017;60:162-9.

34. Ochi M, Tabara Y, Kido T, Uetani E, Ochi N, Igase M, et al. Quadriceps sarcopenia and visceral obesity are risk factors for postural instability in the middle-aged to elderly population. Geriatr Gerontol Int. 2010;10:233-43.

35. King AC, Challis JH, Bartok C, Costigan FA, Newell KM. Obesity, mechanical and strength relationships to postural control in adolescence. Gait Posture. 2012;35(2):261-5.

36. Luna MS, Brech GC, Maria J, Greve DA. Fatores antropométricos que interferem no equilíbrio postural. Braz J Biomech. 2012;13(25):63-70.

37. Cruz-Gómez NS, Plascencia G, Villanueva-Padrón LA, Jáuregui-Renaud K. Influence of Obesity and Gender on the Postural Stability during Upright Stance. Obes Facts. 2011; 4(3):212-7.

38. Huo YR, Suriyaarachchi P, Gomez F, Curcio CL, Boersma D, Gunawardene P, et al. Phenotype of sarcopenic obesity in older individuals with a history of falling. Arch Gerontol Geriatr. 2016;65:255-9.

39. Boucher F, Handrigan GA, Mackrous I, Hue O. Childhood obesity affects postural control and aiming performance during an upper limb movement. Gait Posture. 2015;42(2):116-21.
40. Abate M, Di Iorio A, Pini B, Battaglini C, Di Nicola I, Foschini N, et al. Effects of hypertension on balance assessed by computerized posturography in the elderly. Arch Gerontol Geriatr. 2009;49(1):113-7.

41. Herrera-Rangel A, Aranda-Moreno C, Mantilla-Ochoa T, Zainos-Saucedo L, Jáuregui-Renaud K. The influence of peripheral neuropathy, gender, and obesity on the postural stability of patients with type 2 diabetes mellitus. J Diabetes Res. 2014;2014:787202.

42. Bauer LO, Wu Z, Wolfson LI. An Obese Body Mass Increases the Adverse Effects of HIV/AIDS on Balance and Gait. Phys Ther. 2011;91(7):1063-71.

43. Lin HW, Bhattacharyya N. Impact of dizziness and obesity on the prevalence of falls and fall-related injuries. Laryngoscope. 2014;124(12):2797-801.

44. Costello KE, Matrangola SL, Madigan ML. Independent effects of adding weight and inertia on balance during quiet standing. Biomed Eng Online. 2012;11:20.

45. Teasdale N, Hue O, Marcotte J, Berrigan F, Simoneau M, Doré J, et al. Reducing weight increases postural stability in obese and morbid obese men. Int J Obes. 2007;31(1):153-60.

46. Opala-Berdzik A, Błaszczyk JW, Bacik B, CieślińskaŚwider J, Świder D, Sobota G, et al. Static Postural Stability in Women during and after Pregnancy: A Prospective Longitudinal Study. PLoSOne. 2015;10(6):e0124207.

47. Maffiuletti NA, Agosti F, Proietti M, Riva D, Resnik M, Lafortuna CL, et al. Postural instability of extremely obese individuals improves after a body weight reduction program entailing specific balance training. J Endocrinol Invest. 2005;28(1):2-7.

48. Granacher U, Gollhofer A, Hortobágyi T, Kressig RW, Muehlbauer T. The Importance of Trunk Muscle Strength for Balance, Functional Performance, and Fall Prevention in Seniors: A Systematic Review. Sport Med. 2013;43(7):627-41.

49. Zemková E, Kyselovičová $\mathrm{O}$, Jeleň M, Kováčiková Z, Ollé G, Řtefániková G, et al. Three months of resistance training in overweight and obese individuals improves reactive balance control under unstable conditions. J Back Musculoskelet Rehabil. 2017;30(2):353-62. 
50. Jefferis BJ, Iliffe S, Kendrick D, Kerse N, Trost S, Lennon LT, et al. How are falls and fear of falling associated with objectively measured physical activity in a cohort of community-dwelling older men? BMC Geriatr. 2014;14:114.

51. Meyer PF, Oddsson LIE, De Luca CJ. The role of plantar cutaneous sensation in unperturbed stance. Exp Brain Res. 2004;156(4):505-12.
52. Di Iorio A, Abate M, Pini B, Di Nicola I, Marinelli M, Guglielmi M, et al. Effects of vascular risk factors on balance assessed by computerized posturography in the elderly. Aging Clin Exp Res. 2009;21(2):136-42.

53. Meng H, O'Connor DP, Lee BC, Layne CS, Gorniak SL. Effects of adiposity on postural control and cognition. Gait Posture. 2016;43:31-7.

Received: $12 / 12 / 2018$

Recebido: 12/12/2018

Approved: $11 / 26 / 2019$

Aprovado: 26/11/2019 